\title{
Biofilms and persistent wound infections in United States military trauma patients: a case-control analysis
}

Kevin S Akers ${ }^{1,2^{*}}$, Katrin Mende ${ }^{2,3}$, Kristelle A Cheatle ${ }^{3}$, Wendy C Zera ${ }^{3}$, Xin Y $\mathrm{u}^{3}$, Miriam L Beckius ${ }^{4}$, Deepak Aggarwal ${ }^{3}$, Ping Li $i^{3}$, Carlos J Sanchez ${ }^{1}$, Joseph C Wenke ${ }^{1}$, Amy C Weintrob ${ }^{3,5}$, David R Tribble ${ }^{3}$, Clinton K Murray ${ }^{2}$ and the Infectious Disease Clinical Research Program Trauma Infectious Disease Outcomes Study Group

\begin{abstract}
Background: Complex traumatic injuries sustained by military personnel, particularly when involving extremities, often result in infectious complications and substantial morbidity. One factor that may further impair patient recovery is the persistence of infections. Surface-attached microbial communities, known as biofilms, may play a role in hindering the management of infections; however, clinical data associating biofilm formation with persistent or chronic infections are lacking. Therefore, we evaluated the production of bacterial biofilms as a potential risk factor for persistent infections among wounded military personnel.
\end{abstract}

Methods: Bacterial isolates and clinical data from military personnel with deployment-related injuries were collected through the Trauma Infectious Disease Outcomes Study. The study population consisted of patients with diagnosed skin and soft-tissue infections. Cases (wounds with bacterial isolates of the same organism collected 14 days apart) were compared to controls (wounds with non-recurrent bacterial isolates), which were matched by organism and infectious disease syndrome. Potential risk factors for persistent infections, including biofilm formation, were examined in a univariate analysis. Data are expressed as odds ratios (OR; 95\% confidence interval [CI]).

Results: On a per infected wound basis, 35 cases (representing 25 patients) and 69 controls (representing 60 patients) were identified. Eight patients with multiple wounds were utilized as both cases and controls. Overall, 235 bacterial isolates were tested for biofilm formation in the case-control analysis. Biofilm formation was significantly associated with infection persistence (OR: 29.49; Cl: 6.24-infinity) in a univariate analysis. Multidrug resistance (OR: 5.62; Cl: 1.02-56.92), packed red blood cell transfusion requirements within the first 24 hours (OR: 1.02; Cl: 1.01-1.04), operating room visits prior to and on the date of infection diagnosis (OR: 2.05; Cl: 1.09-4.28), anatomical location of infected wound (OR: 5.47; Cl: 1.65-23.39), and occurrence of polymicrobial infections (OR: 69.71; Cl: 15.39-infinity) were also significant risk factors for persistent infections.

Conclusions: We found that biofilm production by clinical strains is significantly associated with the persistence of wound infections. However, the statistical power of the analysis was limited due to the small sample size, precluding a multivariate analysis. Further data are needed to confirm biofilm formation as a risk factor for persistent wound infections.

Keywords: Biofilm, Risk factors, Trauma-related infections, Persistent infections, Chronic infections, Extremity wound infections

\footnotetext{
* Correspondence: Kevin.s.akers.mil@mail.mil

'Extremity Trauma and Regenerative Medicine Task Area, United States Army

Institute of Surgical Research, JBSA Fort Sam, Houston, TX, USA

${ }^{2}$ Department of Medicine, Infectious Disease Service, Brooke Army Medical

Center, JBSA Fort Sam, Houston, TX, USA

Full list of author information is available at the end of the article
} 


\section{Background}

Due to the usage of improvised explosive devices combined with the utilization of body armor protecting the abdomen and thorax during the recent conflicts in Iraq and Afghanistan (Operations Iraqi Freedom and Enduring Freedom), complex extremity wounds are prevalent among military personnel with deployment-related injuries. This injury pattern often results in infectious complications with considerable morbidity (e.g., limb amputation), extended periods of rehabilitation, and high utilization of hospital resources [1-8]. The prognosis of wounded military personnel is further impacted when infections persist or recur despite appropriate antimicrobial and surgical treatment.

Presently, few data related to infection persistence among military personnel are available [5,9]. An assessment of 664 United States (U.S.) service members with extremity injuries reported that $15 \%$ of patients developed osteomyelitis, of which $17 \%$ experienced an infection recurrence following initial treatment [5]. Among a cohort of 161 civilian patients who sustained traumatic injuries resulting in amputations, $16 \%$ had at least one rehospitalization due to an infection and $6.5 \%$ had unhealed soft-tissue at the end of the 24-month follow-up period [10]. Moreover, an analysis of 454 civilian patients with osteomyelitis, primarily resulting from soft-tissue wounds and surgical procedures, reported that $31 \%$ experienced an infection recurrence, of which $16 \%$ were determined to be relapses (original pathogen), 16\% reinfections (different pathogen), and 68\% could not be specified as either a relapse or reinfection [11].

In general, deployment-related complex trauma involves extensive bone and soft-tissue damage and often requires the insertion of artificial materials to maintain spatial orientation and anatomic alignment of bone fragments necessary to achieve an acceptable level of healing $[7,10]$. An unintended consequence of these procedures is that the medical hardware required to stabilize mangled extremities may serve as a substrate for the formation of bacterial biofilms [12-14], which has been suggested by clinicians to be a factor affecting wound healing and the persistence of infections [13]. In recent years, multiple in vitro models have been developed to investigate the interaction between biofilm formation and chronic wounds [15-19].

According to a National Institute of Health grant announcement issued in 2002, more than $80 \%$ of human bacterial infections are associated with biofilms $[13,20]$. In brief, biofilms are produced when bacteria expand horizontally and vertically on a solid surface to form a sessile, multicellular colony, which secretes a matrix of protein, polysaccharides, and extracellular DNA. The matrix allows the pathogen to circumvent the host's immune responses and impedes the penetration of antimicrobials to the site of infection [12,21,22]. Extensive physical trauma (e.g., soft-tissue damage and vascular disruption) likely further enhances this obstruction. Moreover, bacteria in the lower stratum of the colony cease replication and become intrinsically resistant to currently approved antimicrobial agents [12,22-25]. As a result, biofilms cannot be predictably eradicated by systemic antimicrobial treatment regimens and, therefore, pose a risk for persistent wound infections, particularly when foreign bodies or medical hardware that must be retained for healing are present [12,13,23-29].

Despite the abundant literature confirming the existence of the biofilm phenomenon in in vitro analyses, and the increasing acceptance of this theory of disease among clinicians, an epidemiologic link has not been clearly established between the risk of wound infection persistence and the ability of pathogens to form biofilms. In the current study, our objective was to examine bacterial biofilm formation and other potential risk factors for persistent wound infections among injured military personnel in a case-control analysis.

\section{Methods \\ Study population}

Data were collected from U.S. service members with deployment-related injuries sustained between June 2009 through August 2012 and medically evacuated to Landstuhl Regional Medical Center (LRMC) for initial care before being transferred to a participating tertiary-care military treatment facility (MTF) in the U.S.: Walter Reed Army Medical Center and National Naval Medical Center in the National Capital Region (Walter Reed National Military Medical Center after September 2011), and Brooke Army Medical Center in San Antonio, TX (San Antonio Military Medical Center after September 2011). These clinical data were collected through the ongoing five-year observational cohort study of short- and long-term infectious complications following deployment-related traumatic injuries during the recent military conflicts in Iraq and Afghanistan; the U.S. Department of Defense (DoD)-Department of Veterans Affairs, Trauma Infectious Disease Outcomes Study (TIDOS). As part of the TIDOS project, a microbiological repository was established containing bacterial isolates collected from surveillance cultures at admission and cultures during the course of hospitalization [30]. This study was approved by the Infectious Disease Institutional Review Board of the Uniformed Services University of the Health Sciences (Bethesda, MD).

\section{Case-control identification and investigation}

Information on trauma history, injury patterns, treatment, and infection characteristics for the case and control populations was prospectively collected through the DoD Trauma Registry (DoDTR, formerly the Joint Theater Trauma Registry) [31] and augmented by the 
TIDOS supplemental infectious disease module. Radiologic studies and clinical encounters in the medical records were retrospectively reviewed to gather data on medical hardware implantation. Bacterial isolates were obtained from the TIDOS microbiological repository. Data were collected from all levels of care: LRMC, U.S. MTFs, and post-hospitalization follow-up.

As previously described [30], infections were classified via a comprehensive review of medical records for relevant clinical findings and laboratory test results, along with the utilization of standardized definitions of the National Healthcare Safety Network (NHSN) for nosocomial infections [32]. The criterion for inclusion of wounded personnel in the study population was a diagnosis of a skin and soft-tissue infection (SSTI) and the collection of bacterial isolates from the infected wound site within one day of diagnosis (+/- 24 hours). In addition, the study population was limited to patients with SSTIs linked to one of five bacterial organisms (i.e., Staphylococcus aureus, Klebsiella pneumoniae, Acinetobacter baumannii, Pseudomonas aeruginosa, and Escherichia coli), reflecting clinical experience with causes of persistent wound infections in this population. Cases were identified on a per infected wound basis and required serial bacterial isolates of the same organism to be collected at least 14 days apart following initial diagnosis of an SSTI from the same infected wound. Controls (infected wounds with non-recurrent growth of bacterial isolates) were matched to cases on the basis of organism and infectious disease syndrome (i.e., SSTI). Due to the occurrence of blast injuries, patients frequently sustained multiple wounds with different microbiological growth. If more than one infected wound from a patient met the criteria for inclusion in the study population (i.e., SSTI diagnosis and isolation of specific bacterial organisms), the infected wounds were independently treated as cases and controls as appropriate. Therefore, one patient may contribute both a case and control wound to the analysis.

\section{Bacterial isolates and growth conditions}

Bacterial isolates were recovered from frozen storage at $-80^{\circ} \mathrm{C}$ and serially passaged twice on $5 \%$ sheep's blood agar (Remel, Lenexa, KS) prior to experimental testing. Organisms were defined as multidrug-resistant if they exhibited resistance to at least three of the major antibiotic classes (aminoglycosides, $\beta$-lactams, carbapenems, and fluoroquinolones) or produced either extended spectrum $\beta$-lactamases or $K$. pneumoniae carbapenemases [33]. Antimicrobial susceptibility testing was performed using the BD Phoenix ${ }^{\mathrm{TM}}$ system (BectonDickinson, Franklin Lakes, NJ) per the manufacturer's instructions. Susceptibility to antimicrobials was interpreted according to the criteria of the Clinical Laboratory and Standards Institute [34].

\section{Biofilm production}

Bacterial biofilms from clinical isolates of $S$. aureus, $K$. pneumoniae, A. baumannii, $P$. aeruginosa, and $E$. coli were formed in 96-well plates, under static conditions for 48 hours as previously described [25]. For biofilm growth, inoculums of approximately $10^{8} \mathrm{CFU} / \mathrm{mL}$ were prepared by adjusting culture grown bacterial suspensions to an optical density $\left(\mathrm{OD}_{600 \mathrm{~nm}}\right)$ of $0.25-0.3$ and adding $100 \mu \mathrm{L}$ of each inoculum to individual wells of a 96-well plate. After incubation for 48 hours, wells were gently washed one time with phosphate-buffered saline (PBS; pH 7.4) and stained with $100 \mu \mathrm{L}$ of $0.1 \%$ Crystal Violet $(\mathrm{CV})$ for 30 minutes at room temperature. Excess $\mathrm{CV}$ was removed by gentle washing with $\mathrm{PBS}$, and the residual adherent $\mathrm{CV}$ was solubilized in 95\% ethanol. Biofilm biomass was quantified by measuring absorbance of the supernatant at $570 \mathrm{~nm}$. Absorbance above that level from the positive control strain, Staphylococcus epidermidis ATCC 12228 (ATCC, Manassas, VA), was considered positive for biofilm formation. Each strain was tested in triplicate and the mean value was recorded as the absorbance.

Among isolates of $A$. baumannii, genes for the biofilmassociated protein (bap) were amplified by polymerase chain reaction according to primer sequences and conditions as reported in the supplemental material (Additional file 1: Figure S1). A visual assessment of biofilm production among isolates lacking bap, and several representative isolates containing the bap gene, was performed by confocal laser scanning microscopy (Additional file 2: Figure S2).

\section{Pulsed-field gel electrophoresis}

Clonal relationships between bacterial strains of each individual species were assessed by pulsed-field gel electrophoresis (PFGE) in accordance with the U.S. Food and Drug Administration's method 'Procedure for PFGE of Gram-negative rods' (Version 1, 10/30/2007) and, as previously described [35,36], using the CHEF-DRIII system (Bio-Rad Laboratories, Hercules, CA). The endonucleases utilized for PFGE examination of A. baumannii, S. aureus, and $P$. aeruginosa isolates were ApaI, SmaI, and SpeI, respectively, while XbaI was used for $K$. pneumoniae and E. coli. Analysis of gel images was performed with BioNumerics software (Applied Maths, Austin, TX). Using previously established criteria [36,37], the PFGE patterns were interpreted and grouped into pulsedfield types (PFTs).

\section{Statistical analysis}

Comparisons were performed using Fisher's exact, Chisquare, and Wilcoxon Mann-Whitney tests for categorical 
and continuous variables, respectively. Exact conditional logistic regression was conducted to analyze the association between the potential risk factors and persistent wound infections for the univariate analysis. Independency between the SSTI case and control wounds was assumed. Data are expressed as odds ratios and $95 \%$ confidence intervals. Statistical analysis was conducted using the PROC LOGISTIC procedure from $\mathrm{SAS}^{\circ}$ version 9.3 (SAS, Cary, NC). A value of $\mathrm{p}<0.05$ was used to define statistical significance.

\section{Results}

\section{Patient demographics and characteristics}

From the eligible military trauma population, 35 cases (representing 25 patients) and 69 controls (representing 60 patients) were identified. It should be noted that the 25 case and 60 control subjects included eight patients with multiple wounds were used in both groups. Patients included in the study were predominantly young men (median age of 23 years) injured via a blast mechanism $(>83 \%)$ in support of Operation Enduring Freedom in Afghanistan (>88\%; Table 1). The injury severity scores

Table 1 Demographic characteristics and injury circumstances of deployment-injured U.S. service members (June 2009-August 2012) ${ }^{1}$

\begin{tabular}{|c|c|c|}
\hline Characteristics & $\begin{array}{c}\text { SSTI Case Patients }{ }^{2} \\
(\mathrm{~N}=25)\end{array}$ & $\begin{array}{l}\text { SSTI Control Patients }{ }^{2} \\
(N=60)\end{array}$ \\
\hline \multicolumn{3}{|l|}{ Demographics, no. (\%) } \\
\hline Age, median (IQR) & $22.7(21.6,25.5)$ & $23.3(21.3,26.5)$ \\
\hline Male & $25(100)$ & $56(93.3)$ \\
\hline Enlisted & $24(96.0)$ & $53(88.3)$ \\
\hline \multicolumn{3}{|l|}{ Military operation } \\
\hline $\begin{array}{l}\text { Operation Iraqi } \\
\text { Freedom }\end{array}$ & 0 & $2(3.3)$ \\
\hline $\begin{array}{l}\text { Operation enduring } \\
\text { Freedom }\end{array}$ & $25(100)$ & $53(88.3)$ \\
\hline Unknown & 0 & $5(8.3)$ \\
\hline \multicolumn{3}{|l|}{ Branch of service } \\
\hline Marine & $11(44.0)$ & $25(41.6)$ \\
\hline Army & $12(48.0)$ & $26(43.3)$ \\
\hline Air Force/Navy & $2(8.0)$ & $5(8.3)$ \\
\hline \multicolumn{3}{|l|}{$\begin{array}{l}\text { Injury circumstance and } \\
\text { severity }\end{array}$} \\
\hline Blast injury, no. (\%) & $24(96.0)$ & $50(83.3)$ \\
\hline $\begin{array}{l}\text { LRMC ISS, median } \\
\text { (IQR) }\end{array}$ & $24(14,29)$ & $21(17,29)$ \\
\hline $\begin{array}{l}\text { Units of PRBC transfused } \\
\text { within } 1^{\text {st }} 24 \text { hours, } \\
\text { median (IQR) }\end{array}$ & $34(16,83)$ & $18(9,33)$ \\
\hline \multicolumn{3}{|c|}{$\begin{array}{l}\text { IQR-interquartile range; ISS-injury severity score; LRMC-Landstuhl Regional } \\
\text { Medical Center; PRBC-packed red blood cells plus whole blood; SSTI-skin and } \\
\text { soft-tissue infections; U.S.-United States. } \\
{ }^{1} \text { Data are on a per patient basis. } \\
{ }^{2} \text { Eight patients with multiple infected wounds were utilized as both cases } \\
\text { and controls. }\end{array}$} \\
\hline
\end{tabular}

(i.e., a measure of overall anatomical injury severity based upon body region-specific Abbreviated Injury Severity Scale scores [38]) at admission to LRMC indicated severe trauma for both the cases and controls with median values of 24 and 21 , respectively. In addition, both groups required large volume transfusions of packed red blood cells plus whole blood (PRBC) within the first 24 hours following injury (median of 34 units for cases; 18 units for controls).

Per the study criteria, all patients were diagnosed with skin and soft-tissue infections, of which the majority of infections (92\% of case and $88 \%$ of control patients) were identified as deep soft-tissue versus superficial (Table 2). Two cases and two controls were also diagnosed with osteomyelitis. The median time following injury to the initial clinical diagnosis of the infection was 8 days for the cases and 12 days for the controls. Both

Table 2 Infection characteristics and outcomes among deployment-injured U.S. service members (June 2009August 2012) ${ }^{1}$

\begin{tabular}{|c|c|c|}
\hline Characteristics & $\begin{array}{c}\text { SSTI Case Patients }{ }^{2} \\
(\mathrm{~N}=25)\end{array}$ & $\begin{array}{l}\text { SSTI Control Patients }{ }^{2} \\
(\mathrm{~N}=60)\end{array}$ \\
\hline $\begin{array}{l}\text { Time from injury to } \\
\text { clinical diagnosis, } \\
\text { median days (IQR) }\end{array}$ & $8.0(5.0,16.0)$ & $11.5(7.0,21.5)$ \\
\hline $\begin{array}{l}\text { Time from injury to initial } \\
\text { positive culture, median } \\
\text { days (IQR) }\end{array}$ & $8.0(7.0,17.0)$ & $12.0(7.0,22.0)$ \\
\hline \multicolumn{3}{|l|}{ Infection type, no. $(\%)^{3}$} \\
\hline SSTI-superficial & $4(16.0)$ & $8(13.3)$ \\
\hline SSTI-deep & $23(92.0)$ & $53(88.3)$ \\
\hline Osteomyelitis & $2(8.0)$ & $2(3.3)$ \\
\hline Foreign body & 0 & $1(1.7)$ \\
\hline \multicolumn{3}{|l|}{ Antibiotic use, no. (\%) } \\
\hline $1-14$ days & $4(16.0)$ & $18(30.0)$ \\
\hline $15-23$ days & $3(12.0)$ & $16(26.7)$ \\
\hline 24-43 days & $7(28.0)$ & $10(16.7)$ \\
\hline$>43$ days & $11(44.0)$ & $8(13.3)$ \\
\hline $\begin{array}{l}\text { Completed during } \\
\text { hospitalization }\end{array}$ & $17(68.0)$ & $47(78.3)$ \\
\hline $\begin{array}{l}\text { Ongoing at } \\
\text { discharge }^{4}\end{array}$ & $5(20.0)$ & $5(8.3)$ \\
\hline \multicolumn{3}{|l|}{ Outcome, No. (\%) } \\
\hline $\begin{array}{l}\text { Limb loss during } \\
\text { inpatient period }\end{array}$ & $3(12.0)$ & $6(10.0)$ \\
\hline $\begin{array}{l}\text { Limb loss due to } \\
\text { infection }\end{array}$ & $2(8.0)$ & $3(5.0)$ \\
\hline Death & $1(4.0)$ & $2(3.3)$ \\
\hline
\end{tabular}

IQR-interquartile range; SSTI-skin and soft-tissue infection; U.S.-United States. 'Data are on a per patient basis.

${ }^{2}$ Eight patients with multiple infected wounds were utilized as both cases and controls.

${ }^{3}$ Patients were diagnosed with multiple infected wounds.

${ }^{4}$ Data missing from one case patient. 
groups largely completed their course of antibiotics while hospitalized (68\% of cases and $78 \%$ of controls) with durations ranging from two weeks ( $16 \%$ and $30 \%$, respectively) to more than 43 days ( $44 \%$ and $13 \%$, respectively). Similar proportions of case (12\%) and control patients (10\%) experienced a surgical amputation during their hospitalization, with at least half of the procedures attributed to infections. Overall, there were three deaths among the study population (one case and two controls).

\section{Wound characteristics}

Extremity injuries accounted for $60 \%$ of the SSTI case wounds (37\% and $23 \%$ for the lower and upper limbs, respectively), while the groin/pelvis contributed the remaining proportion. Among the SSTI control wounds, $65 \%, 13 \%$, and $22 \%$ involved lower extremity, upper extremity, and non-extremity wound sites (i.e., groin/pelvis and head/chest/abdomen), respectively (Table 3). Between the two groups, there was a significant difference $(p=0.024)$ in the overall infection site profile. Regarding the SSTI case wounds, the occurrence of polymicrobial infections and biofilm production was significantly greater $(71 \%$ and $97 \%$, respectively; $\mathrm{p}<0.0001)$ compared to the control wounds (0 and 59\%, respectively). The case wounds were also predominantly characterized by multidrug-resistant organisms (MDROs); however, the proportion was not significantly different from the control wounds. Moreover, approximately $20 \%$ of both the case and control wounds required the implantation of medical hardware.

Overall, a total of 340 bacterial cultures were collected, of which 151 (89 from case wounds; 62 from control wounds) grew bacterial organisms and $A$. baumannii was the predominant isolate among the cases (24\%) and controls (30\%; Table 4). P. aeruginosa was also a major contributor $(24 \%$ and $29 \%$ for cases and controls, respectively) followed by E. coli ( $9 \%$ and $19 \%$, respectively), K. pneumoniae ( $8 \%$ and $1 \%$, respectively), and $S$. aureus (3\% and 6\%, respectively). When the bacterial isolates were compared between the SSTI case and control wounds, there was a significant difference in the profiles $(\mathrm{p}<0.0001)$. In addition, 235 bacterial isolates linked to infections and utilized in the case-control analysis (after selection through use of matching criteria) were tested for multidrug resistance (Table 5). On a per patient basis, all infections associated with $A$. baumannii and K. pneumoniae were due to multidrug-resistant isolates. Infections attributed to $E$. coli isolates were also largely multidrugresistant $(75 \%$ and $83 \%$ of the case and control patients, respectively). However, $S$. aureus infections only demonstrated methicillin resistance among the case patients (67\%) and $P$. aeruginosa isolates were generally susceptible with both groups.

Table 3 Infection characteristics among deploymentinjured U.S. service members (June 2009-August 2012) ${ }^{1}$

\begin{tabular}{lccc}
\hline Characteristics & SSTI Case & SSTI Control & $p$-value \\
& Wounds $(\mathrm{N}=35)$ & Wounds $(\mathrm{N}=69)$ &
\end{tabular}

Infection Location

No. (\%)

Lower extremity
Thigh
Gluteal muscles
Knee
Lower leg
Ankle
Foot
Upper extremity
Upper arm
Forearm
Non-extremity
Groin/genitalia
Head/chest/
abdomen

Time from injury to $1^{\text {st }}$ culture with growth, median days $(\mathrm{IQR})^{2}$

OR visits prior to and on date of infection diagnosis, median (IQR)

Medical devices implanted in the same anatomic region as the infected wound No. (\%)

Infection Characteristics, No. (\%)

\begin{tabular}{lccc} 
Biofilm production & $34(97.1)$ & $41(59.4)$ & $<0.0001$ \\
$\begin{array}{l}\text { Organisms susceptible } \\
\text { to empiric antibiotics }\end{array}$ & $11(31.4)$ & $17(24.6)$ & 0.154 \\
$\begin{array}{l}\text { Infections due to } \\
\text { multidrug-resistant } \\
\text { organisms }\end{array}$ & $26(74.3)$ & $41(59.4)$ & 0.135 \\
$\begin{array}{l}\text { Polymicrobial } \\
\text { infection }\end{array}$ & $25(71.4)$ & 0 & $<0.0001$ \\
\hline
\end{tabular}

IQR-interquartile range; OR-operating room; SSTI-skin and soft-tissue infections; U.S.-United States.

${ }^{1}$ Data are on a per SSTI wound basis.

${ }^{2}$ Specific to growth of the five organisms included in the analysis: Staphylococcus aureus, Klebsiella pneumoniae, Acinetobacter baumannii, Pseudomonas aeruginosa, and Escherichia coli.

\section{Biofilm formation}

Biofilm production was assessed among the 235 isolates utilized in the case-control analysis and a significantly greater proportion of biofilms formed in association with $A$. baumannii isolates among the cases compared to the controls ( $<<0.0001$; Table 6). However, there were no statistical differences regarding biofilm 
Table 4 Bacterial isolates, no. (\%) on a per wound basis (June 2009-August 2012) ${ }^{1}$

\begin{tabular}{lccc}
\hline & $\begin{array}{c}\text { SSTI Case } \\
\text { wounds }\end{array}$ & $\begin{array}{c}\text { SSTI Control } \\
\text { wounds }\end{array}$ & p-value \\
\hline Bacterial organism & & & $<0.0001$ \\
Acinetobacter baumannii & $79(24.0)$ & $36(30.3)$ & \\
Pseudomonas aeruginosa & $78(23.7)$ & $35(29.4)$ & \\
Escherichia coli & $28(8.5)$ & $23(19.3)$ & \\
Klebsiella pneumoniae & $26(7.9)$ & $1(0.8)$ & \\
Staphylococcus aureus & $10(3.0)$ & $7(5.9)$ & \\
Other & $108(32.8)$ & $17(14.3)$ & \\
Total Bacterial Isolates & 329 & 119 & \\
\hline
\end{tabular}

SSTI-skin and soft-tissue infections.

'Data collected from all levels of care: Landstuhl Regional Medical Center, United States military medical treatment facilities, and

post-hospitalization follow-up.

production with either $P$. aeruginosa or $E$. coli. Data from $K$. pneumoniae and $S$. aureus were too few to be analyzed.

The serial isolates of the case wounds were also examined for concordance of the PFTs and biofilm production. The majority of the case wounds had concordant PFTs with only nine cases (26\%) reporting a PFT that was different from the initial isolate. In addition, bacterial isolates from 14 case wounds (40\%) exhibited biofilm production that was discordant from the initially isolated sample.

Carriage of the bap gene was widespread in A. baumannii, identified in $96 \%$ of isolates (Additional file 1: Figure S1). On a per isolate basis, bap carriage was not associated with biofilm formation, as determined by $\mathrm{CV}$ uptake $(\mathrm{p}=1.00)$. The three bap-negative isolates were recovered from infectious episodes subsequent to the initial infection with two of the isolates identified among cultures collected from the same wound site of a single patient on the same date. Each bap-negative isolate matched the PFGE genotype and antimicrobial susceptibility phenotype of the initial infecting isolate. Confocal microscopy images of bap-positive and bap-negative isolates suggested that bap may increase biofilm formation among isolates carrying this gene. Qualitatively, biofilms appeared to form among bap-negative isolates, but to a lesser degree than bap-positive isolates (Additional file 2: Figure S2).

\section{Univariate risk factor analysis}

Site of infection (i.e., non-groin/genitalia wound versus groin/genitalia wound), biofilm production, presence of medical hardware, time from injury to first bacterial culture with growth, multidrug resistance of organisms, PRBC transfusion requirements within the first 24 hours of injury, pathogen susceptibility to empiric antibiotics,
Table 5 Infections due to multidrug-resistant (MDR) bacterial organisms, no. (\%) (June 2009-August 2012) ${ }^{1}$

\begin{tabular}{lccc}
\hline $\begin{array}{l}\text { Bacterial } \\
\text { Organism }\end{array}$ & $\begin{array}{c}\text { SSTI Case } \\
\text { Patients }^{2} \mathbf{( N = 2 5 )}\end{array}$ & $\begin{array}{c}\text { SSTI Control } \\
\text { Patients }^{2}(\mathbf{N}=\mathbf{6 0})\end{array}$ \\
\hline $\begin{array}{l}\text { Acinetobacter } \\
\text { baumannii }\end{array}$ & Total Infections & 9 & 21 \\
$\begin{array}{l}\text { Pseudomonas } \\
\text { aeruginosa }\end{array}$ & Total Infections & $9(100)$ & $21(100)$ \\
Escherichia coli & Total Infections & 8 & 24 \\
& ESBL-producing & $6(75.0)$ & $2(8.3)$ \\
Klebsiella & Total Infections & 1 & 12 \\
pneumoniae & ESBL-producing & $1(100)$ & $10(83.3)$ \\
Staphylococcus & Total Infections & 3 & 1 \\
aureus & MRSA & $2(66.7)$ & 2 \\
\hline
\end{tabular}

ESBL-extended-spectrum $\beta$-lactamase; MRSA-methicillin-resistant Staphylococcus aureus; SSTI-skin and soft-tissue infections.

${ }^{1}$ Data are on a per patient basis and are collected from all levels of care: Landstuhl Regional Medical Center, United States military treatment facilities, and post-hospitalization follow-up.

${ }^{2}$ Eight patients with multiple infected wounds were utilized as both cases and controls.

number of operating room visits prior to and on the date of clinical diagnosis, and polymicrobial infection status were examined as potential risk factors for persistent infections in an univariate analysis (Table 7). Specific bacterial organisms were not included as potential risk factors in the analysis due to their role as matching criteria for the cases and controls. Based upon the results of the univariate analysis, the following risk factors were significantly associated with persistent infections: biofilm production $(\mathrm{p}<0.0001)$, multidrug resistance of organisms $(\mathrm{p}=0.046), \mathrm{PRBC}$ transfusion requirements $(p<0.001)$, number of operating room visitations $(p=0.022)$, anatomical site of infection $(p=0.003)$; and polymicrobial infection status $(\mathrm{p}<0.0001)$. A multivariate model failed to converge due to our limited sample size.

\section{Discussion}

It is well-recognized that trauma-related infections often result in considerable morbidity among military personnel. Therefore, understanding potential risk factors for wound infection persistence is critical for effective infection management and to improve patient prognosis. Our analysis compared data from 35 cases (SSTI wounds with recurrent bacterial isolates at least 14 days apart) with 69 controls (SSTI wounds with non-recurrent isolates). The results of the univariate analysis suggest that infection persistence is statistically associated with biofilm formation, along with the anatomical site of the infected wound (non-groin/pelvis versus groin/ pelvis), multidrug resistance of pathogens, polymicrobial 
Table 6 Biofilm results, no. (\%), on a per wound basis

\begin{tabular}{|c|c|c|c|c|c|}
\hline Bacterial Isolates & Biofilm Formation & Total & SSTI Case Wounds $(\mathrm{N}=35)$ & SSTI Control Wounds $(\mathrm{N}=69)$ & $\mathrm{p}$-value \\
\hline \multirow[t]{2}{*}{ Acinetobacter baumannii } & Positive & $19(18.3)$ & $12(34.3)$ & $7(10.1)$ & $<0.0001$ \\
\hline & Negative & $17(16.4)$ & 0 & $17(24.6)$ & \\
\hline \multirow[t]{2}{*}{ Pseudomonas aeruginosa } & Positive & $34(32.7)$ & $12(34.3)$ & $22(31.9)$ & 0.543 \\
\hline & Negative & $2(1.9)$ & 0 & $2(2.9)$ & \\
\hline \multirow[t]{2}{*}{ Escherichia coli } & Positive & $11(10.6)$ & $6(17.1)$ & $5(7.3)$ & 0.064 \\
\hline & Negative & $10(9.6)$ & $1(2.9)$ & $9(13.0)$ & \\
\hline \multirow[t]{2}{*}{ Klebsiella pneumoniae } & Positive & $2(1.9)$ & $1(2.9)$ & $1(1.5)$ & NA \\
\hline & Negative & 0 & 0 & 0 & \\
\hline \multirow[t]{2}{*}{ Staphylococcus aureus } & Positive & $9(8.7)$ & $3(8.6)$ & $6(8.7)$ & NA \\
\hline & Negative & 0 & 0 & 0 & \\
\hline
\end{tabular}

NA-not applicable; SSTI-skin and soft-tissue infections.

infections, large volume PRBC transfusions, and the number of operating room visits leading up to the clinical diagnosis of the infection. However, pathogen susceptibility to empiric antibiotics and presence of medical hardware were not significant risk factors for persistent infections.

Table 7 Univariate odds ratio analysis for persistent wound infection risk factors among deployment-injured U.S. service members

\begin{tabular}{|c|c|c|c|}
\hline Potential Clinical Risk Factor ${ }^{1,2}$ & $\begin{array}{l}\text { Odds } \\
\text { Ratio }\end{array}$ & $\begin{array}{l}95 \% \text { Confidence } \\
\text { Interval }\end{array}$ & p-value \\
\hline $\begin{array}{l}\text { Infection location } \\
\text { (non-groin/pelvis } \\
\text { versus groin/pelvis) }\end{array}$ & 5.47 & $1.65-23.39$ & 0.003 \\
\hline $\begin{array}{l}\text { Time from injury to } \\
1^{\text {st }} \text { positive culture }\end{array}$ & 1.00 & $0.99-1.01$ & 0.398 \\
\hline $\begin{array}{l}\text { Multidrug resistance } \\
\text { of organisms }\end{array}$ & 5.62 & $1.02-56.92$ & 0.046 \\
\hline Biofilm production & 29.49 & 6.24-infinity & $<0.0001$ \\
\hline $\begin{array}{l}\text { PRBC requirements } \\
\text { within } 1^{\text {st }} 24 \text { hours }^{4}\end{array}$ & 1.02 & $1.01-1.04$ & $<0.001$ \\
\hline $\begin{array}{l}\text { Pathogen susceptibility } \\
\text { to empiric antibiotics }\end{array}$ & 0.47 & $0.01-10.22$ & 1.00 \\
\hline $\begin{array}{l}\text { Number of OR visits prior to } \\
\text { and on date of infection } \\
\text { diagnosis }\end{array}$ & 2.05 & $1.09-4.28$ & 0.022 \\
\hline Polymicrobial Infection & 69.71 & 15.39-infinity & $<0.0001$ \\
\hline $\begin{array}{l}\text { Presence of medical devices } \\
\text { in the anatomic region of } \\
\text { the wound infection }\end{array}$ & 1.05 & $0.35-3.17$ & 0.925 \\
\hline
\end{tabular}

OR-operating room; PRBC-packed red blood cells plus whole blood;

U.S.-United States.

${ }^{1}$ Characteristics are on a per wound basis.

${ }^{2}$ The odds ratios for continuous predictors estimate the change in odds for a unit increase in the continuous predictor.

${ }^{3}$ Defined by demonstrating resistance to three or more antibiotic classes (aminoglycosides, $\beta$-lactams, carbapenems, and fluoroquinolones) or producing either extended spectrum $\beta$-lactamases or Klebsiella pneumoniae carbapenemases [33].

${ }^{4}$ Blood product transfusion data is on a per patient basis.
Despite the multitude of scientific literature available with biofilm data, there is a lack of clinical studies examining the role of biofilm formation as a risk factor for persistent wound infections. Consistent with our findings, studies assessing the relationship of biofilm formation and infection persistence in urinary tract infections demonstrated a strong correlation between these two factors $[39,40]$. To the best of our knowledge, the current analysis provides the first statistical data linking bacterial production of biofilms with the persistence of traumatic wound infections and corroborates earlier reports on the potential virulence of the bacterial biofilm phenotype [25]. Biofilm formation, in our analysis, was largely attributed to multidrug-resistant $A$. baumannii, which corresponds to a prior study reporting a statistical increase in the proportion of $A$. baumannii isolates that were biofilm-producing and multidrug-resistant (73\%) when compared to P. aeruginosa (57\%) [41]. In addition, a recent analysis utilized clinical isolates collected from patients including military personnel admitted to a U.S. MTF to evaluate biofilm formation. Overall, $61 \%$ of isolates produced biofilms, which were predominantly associated with MDROs, including $A$. baumannii. It was also determined that biofilm-producing isolates were more commonly collected from wound sites (e.g., bone and soft-tissue) compared to urine and blood [25].

Furthermore, the direct involvement of the A. baumannii bap gene in biofilm formation and maturation on medically-relevant abiotic surfaces (e.g., polypropylene, polystyrene, and titanium) has been suggested [42]. The bap gene carriage is widespread among $A$. baumannii isolates and may contribute to increased biofilm formation; however, in the absence of data elucidating in vivo gene expression, our data do not suggest carriage of this gene by infecting isolates is sufficient to constitute a risk factor for persistent infections. Moreover, confocal microscopy visualization of biofilm formation by bap-negative isolates suggests a redundancy of mechanisms for biofilm 
formation in A. baumannii. Nonetheless, it should be noted that this analysis was limited by the infrequency of bapnegative isolates.

In general, implantation of medical devices (e.g., materials for wound stabilization, catheters, and joint prosthetics) has been frequently associated with the production of biofilms and subsequent infections in both military and civilian populations [12,13,23-25,29]. Therefore, it was surprising that the presence of medical hardware was not statistically significant in the univariate model. One explanation could be the low number of wounds (e.g., open fractures) that required the implantation of medical hardware ( 20\%) among both the cases and controls; thus, limiting the power of the analysis. In addition, information on medical hardware was not collected prospectively, which introduces the biases and limitations related to retrospective data analysis. Furthermore, the date of medical device implantation was an estimation based upon radiology reports, so the direct association of bacterial isolates with the hardware remains uncertain. Lastly, data on medical devices in the clinical records were not specific as to exact anatomic sites (e.g., elbow and knee), but provided a more general location (e.g., limbs). As a result, it cannot be definitively known if the site of hardware implantation was the same site of infection. Nonetheless, in the absence of medical hardware, contamination of soft-tissue wounds by foreign bodies also provides a suitable substrate for biofilm growth and impacts the effectiveness of treatment. In particular, patients treated exclusively with targeted antimicrobial therapy, and not in conjunction with the removal of foreign bodies from infected sites, are likely to develop persistent infections when biofilms are involved [28].

One concern of clinicians in both military and civilian settings is that the inherent tolerance of pathogens encased in biofilms to antimicrobial agents, along with a slow growth rate, creates opportunities for the transmission of resistance markers and subsequent increased prevalence of MDROs in hospital settings. A recent analysis examined surveillance cultures collected from wounded military personnel at LRMC and U.S. MTFs and reported sustained colonization levels of multidrugresistant gram-negative organisms over a three-year period (6.6\% and $12.4 \%$, respectively) [43]. Better understanding of biofilm-producing pathogens may provide data to improve infection control strategies and reduce the transmission of MDROs.

Moreover, infection persistence further add to the large amount of hospital resources (approximately twothirds) necessary to manage extremity injuries among wounded military personnel during the initial inpatient period and hospital readmission. In particular, the resource cost of inpatient care and rehospitalization for military personnel with extremity injuries was estimated to be approximately $\$ 667$ and $\$ 139$ million, respectively, during the conflicts in Iraq and Afghanistan [7]. Interventions designed to effectively mitigate biofilm formation might significantly reduce persistence among patients with wound infections. Presently, antimicrobial methods and control agents to eradicate biofilm pathogens are generally unsuccessful [13,22].

Polymicrobial infection was identified in this study to be a significant risk factor for relapsing infection in SSTIs. In contrast to wound infections involving a single species, the synergy between microorganisms with polymicrobial infections has been shown to increase bioburden, severity of infection, increased antimicrobial resistance, and enhanced inflammatory host responses within wounds [44-47]. Although these studies did not fully address whether biofilm formation, also associated with persistence, was enhanced during polymicrobial infection, it seems probable that these interactions between organisms that influence other virulence properties would also have an effect on biofilm formation. Given the observed association between polymicrobial infection and infection persistence, future studies should evaluate interactions between organisms, such as A. baumannii and common co-pathogens to assess the effects that this may have on virulence properties including biofilm formation and chronicity of infection.

It should be noted there are limitations to our study that should be considered. As previously discussed, the analysis was limited by the small number of bap-negative isolates and wounds that required the implantation of medical hardware. In addition, the statistical power of the risk factor analysis was impacted by the overall, small sample size. Specifically, when the data were examined in a multivariate analysis, the model failed to converge due to the small number of observations within each matched strata groups when analyzed in combination with the other potential risk factors. Since cultures were obtained at the discretion of medical providers, ascertainment bias could have resulted from preferential culturing of patients with clinical infections, thus missing indolent or subacute bacterial colonization among less affected patients. However, our study by design examined patients who met the NHSN definition of clinical infection. Likewise, a misclassification bias could have occurred if control wounds were subclinically colonized with bacteria and not discovered after the initial clinical infection due to lack of culturing. Nonetheless, as elegantly demonstrated in the literature, enforcement of negative cultures among controls of a case-control study can introduce a severity of illness bias, which has a more severe effect on the odds ratios than does misclassification bias [48]. Furthermore, biofilm testing has not been standardized and the available methods do not evaluate biofilm formation in identical manners. Consequently, the results of biofilm analyses may vary depending on the methodology. Among the currently available in vitro biofilm models, the CV method utilized in our analysis has 
been widely reported in the literature and is considered to be the de facto gold standard [49]. Since our study examined U.S. military casualties, our findings may not be generalizable to all settings and populations; however, it is notable that other armed conflicts unfortunately have produced civilian casualties complicated by $A$. baumannii wound infections [50].

Future work should seek to confirm the role of biofilm formation by A. baumannii and other organisms as an independent risk factor for the persistence or relapse of wound infections. In addition, translational work is needed to bring promising compounds into the clinical setting, which target the prevention of biofilm development [51], promote their dispersal [52,53], and eliminate persister cells [54]. The potential for such approaches to eradicate biofilm-mediated infections in vivo has recently been demonstrated [55]. Given the breadth of human clinical infections that have been proposed to involve bacterial biofilms $[13,20]$, substantial savings in resources and iatrogenic morbidity could be realized if such therapies allowed for current durations of antimicrobial therapy to be reduced.

\section{Conclusions}

The results of our analysis indicate that the production of biofilms is significantly associated with the persistence of wound infections. To the best of our knowledge, these are the first data directly linking biofilm formation with persistent wound infections. These findings indicate the importance of biofilms in infection management. Further analyses with a larger study population are needed to validate our data and corroborate biofilm formation as an independent risk factor for persistent traumarelated infections. In addition, the parameters of polymicrobial infections, multidrug resistance, operating room visitations, and large volume PRBC transfusions within the first 24 hours warrant investigation as to their role in the persistence of trauma-related infections.

\section{Additional files}

Additional file 1: Figure S1. Polymerase chain reaction (PCR) screening of the biofilm-associated protein (bap) gene in clinical isolates of Acinetobacter baumannii. Seventy-six A. baumannii clinical isolates were screened for the presence of the bap gene using primer BapF (5' tag gga ggg tac caa tgc ag) and BapR (5' tca tga ttt gat gct gca gcg ata a). The bap gene was amplified under the following conditions: $95^{\circ} \mathrm{C}$ for two minutes, $95^{\circ} \mathrm{C}$ for 30 seconds, $61^{\circ} \mathrm{C}$ for 30 seconds, $68^{\circ} \mathrm{C}$ for one minute (times 30 cycles), and $68^{\circ} \mathrm{C}$ for two minutes. The PCR products were separate in $1 \%$ Agarose gel. A. baumannii ATCC strain 17978, a bap positive strain, was used as the positive control. A clinical isolates of Escherichia coli was used as a negative control.

Additional file 2: Figure S2. Visual analysis and comparison of biofilms formed by clinical isolates of Acinetobacter baumannii screened for the biofilm associated protein (bap) gene. Representative confocal laser microscopy images of biofilms (20x) formed by clinical strains of $A$. baumannii after 24 hours of growth in chamber slides stained with a live/dead viability stain (Molecular Probes). Clinical strains confirmed by polymerase chain reaction as bap positive $(\mathrm{B}-\mathrm{C})$ along with the bap positive control (A) formed highly dense and homogenous biofilms, whereas the bap negative clinical strains (D-F) formed less dense biofilms with a more heterogeneous phenotype.

\section{Competing interests}

The authors declare that they have no competing interests.

\section{Authors' contributions}

KSA participated in the study design, data analysis, and writing of the manuscript. KM, KAC, WCZ, XY, and MLB performed the experimental study and acquisition of data. KM, DA, PL, CJS, ACW, DRT, and CKM participated in the study design and data analysis. KM, DA, CJS, JCW, ACW, DRT, and CKM helped review the manuscript. All authors read and approved the final manuscript.

\section{Acknowledgments}

Part of this material was presented at 2013 ID Week: A Joint Meeting of IDSA, SHEA, HIVMA, and PIDs, October 2-6, 2013, San Francisco, CA. Support for this work (IDCRP-024) was provided by the Infectious Disease Clinical Research Program (IDCRP), a Department of Defense program executed through the Uniformed Services University of the Health Sciences. This project has been funded by the Department of Defense Global Emerging Infections Surveillance and Response System (GEIS), a division of the Armed Forces Health Surveillance Center, National Institute of Allergy and Infectious Diseases, National Institute of Health, under Inter-Agency Agreement Y1-Al5072, and the Department of the Navy under the Wounded, III, and Injured Program. We are indebted to the Infectious Disease Clinical Research Program TIDOS study team of clinical coordinators, microbiology technicians, data managers, clinical site managers, and administrative support personnel for their tireless hours to ensure the success of this project. We would like to thank M. Leigh Carson for her assistance in the preparation of the manuscript.

\section{Disclaimer}

The views expressed are those of the authors do not necessarily reflect the official views of the Uniformed Services University of the Health Sciences, the National Institute of Health or the Department of Health and Human Services, the Department of Defense, the Departments of the Army, Navy or Air Force, or the United States Army Institute of Surgical Research. Mention of trade names, commercial products, or organization does not imply endorsement by the U.S. Government.

\section{Author details}

'Extremity Trauma and Regenerative Medicine Task Area, United States Army Institute of Surgical Research, JBSA Fort Sam, Houston, TX, USA. ${ }^{2}$ Department of Medicine, Infectious Disease Service, Brooke Army Medical Center, JBSA Fort Sam, Houston, TX, USA. ${ }^{3}$ Infectious Disease Clinical Research Program, Uniformed Services University of the Health Sciences, Bethesda, MD, USA. ${ }^{4}$ Department of Clinical Investigation, Brooke Army Medical Center, JBSA Fort Sam, Houston, TX, USA. ${ }^{5}$ Walter Reed National Military Medical Center, Bethesda, MD, USA.

Received: 30 December 2013 Accepted: 3 April 2014 Published: 8 April 2014

\section{References}

1. Murray CK, Hsu JR, Solomkin JS, Keeling JJ, Andersen RC, Ficke JR, Calhoun $\mathrm{JH}$ : Prevention and management of infections associated with combat-related extremity injuries. J Trauma 2008, 64(3 Suppl):S239-S251.

2. Murray CK, Obremskey WT, Hsu JR, Andersen RC, Calhoun JH, Clasper JC, Whitman TJ, Curry TK, Fleming ME, Wenke JC, Ficke JR, Prevention of Combat-Related Infections Guidelines Panel: Prevention of infections associated with combat-related extremity injuries. J Trauma 2011, 71(2 Suppl 2):S235-S257.

3. Stansbury LG, Lalliss SJ, Branstetter JG, Bagg MR, Holcomb JB: Amputations in U.S. military personnel in the current conflicts in Afghanistan and Iraq. J Orthop Trauma 2008, 22(1):43-46.

4. Brown KV, Murray CK, Clasper JC: Infectious complications of combatrelated mangled extremity injuries in the British military. J Trauma 2010, 69(Suppl 1):S109-S115. 
5. Yun HC, Branstetter JG, Murray CK: Osteomyelitis in military personnel wounded in Iraq and Afghanistan. J Trauma 2008, 64(2 Suppl):S163-S168. discussion $\mathrm{S168.}$

6. Owens BD, Kragh JF Jr, Macaitis J, Svoboda SJ, Wenke JC: Characterization of extremity wounds in Operation Iraqi Freedom and Operation Enduring Freedom. J Orthop Trauma 2007, 21(4):254-257.

7. Masini BD, Owens BD, Hsu JR, Wenke JC: Rehospitalization after combat injury. J Trauma 2011, 71(1 Suppl):S98-S102

8. Krueger CA, Wenke JC, Ficke JR: Ten years at war: comprehensive analysis of amputation trends. J Trauma Acute Care Surg 2012, 73(6 Suppl 5):S438-S444.

9. Johnson EN, Burns TC, Hayda RA, Hospenthal DR, Murray CK: Infectious complications of open type III tibial fractures among combat casualties. Clin Infect Dis 2007, 45(4):409-415

10. MacKenzie EJ, Bosse MJ, Castillo RC, Smith DG, Webb LX, Kellam JF, Burgess AR, Swiontkowski MF, Sanders RW, Jones AL, McAndrew MP, Patterson BM, Travison TG, McCarthy ML: Functional outcomes following trauma-related lower-extremity amputation. J Bone Joint Surg Am 2004, 86-A(8):1636-1645.

11. Tice $A D$, Hoaglund PA, Shoultz DA: Risk factors and treatment outcomes in osteomyelitis. J Antimicrob Chemother 2003, 51(5):1261-1268.

12. Kostakioti M, Hadjifrangiskou M, Hultgren SJ: Bacterial biofilms: development, dispersal, and therapeutic strategies in the dawn of the postantibiotic era. Cold Spring Harb Perspect Med 2013, 3(4):1-23.

13. Romling $U$, Balsalobre C: Biofilm infections, their resilience to therapy and innovative treatment strategies. J Intern Med 2012, 272(6):541-561.

14. Revdiwala S, Rajdev BM, Mulla S: Characterization of bacterial etiologic agents of biofilm formation in medical devices in critical care setup. Crit Care Res Pract 2012, 2012:945805.

15. Hill KE, Malic S, McKee R, Rennison T, Harding KG, Williams DW, Thomas DW: $\mathrm{An}$ in vitro mode of chronic wound biofilms to test wound dressings and assess antimicrobial susceptibilities. J Antimicrob Chemother 2010, 65(6):1195-1206.

16. Malic S, Hill KE, Playle R, Thomas DW, Williams DW: In vitro interaction of chronic wound bacteria in biofilms. J Wound Care 2011, 20(12):569-570. 572, 574-577.

17. Sun Y, Dowd SE, Smith E, Rhoads DD, Wolcott RD: In vitro multispecies Lubbock chronic wound biofilm model. Wound Repair Regen 2008, 16(6):805-813.

18. Werthen M, Henriksson L, Jenson PO, Sternberg C, Givskov M, Bjarnsholt T: An in vitro model of bacterial infections in wounds and other soft tissues. APMIS 2010, 118(2):156-164

19. Agostinho AM, Hartman A, Lipp C, Parker AE, Stewart PS, James GA: An in vitro model for the growth and analysis of chronic wound MRSA biofilms. J Appl Microbiol 2011, 111(5):1275-1282.

20. National Institute of Health: Research on microbial biofilms: PA Number: PA-03-047. 2002 [http://grants.nih.gov/grants/guide/pa-files/PA-03-047.html]

21. Costerton JW, Stewart PS, Greenberg EP: Bacterial biofilms: a common cause of persistent infections. Science 1999, 284(5418):1318-1322.

22. Scali C, Kunimoto B: An update on chronic wounds and the role of biofilms. J Cutan Med Surg 2013, 17:1-6.

23. Donlan RM: Biofilm formation: a clinically relevant microbiological process. Clin Infect Dis 2001, 33(8):1387-1392.

24. Donlan RM: Biofilms and device-associated infections. Emerg Infect Dis 2001, 7(2):277-281

25. Sanchez CJ Jr, Mende K, Beckius ML, Akers KS, Romano DR, Wenke JC, Murray CK: Biofilm formation by clinical isolates and the implications in chronic infections. BMC Infect Dis 2013, 13:47.

26. Stoodley P, Nistico L, Johnson S, Lasko LA, Baratz M, Gahlot V, Ehrlich GD, Kathju S: Direct demonstration of viable Staphylococcus aureus biofilms in an infected total joint arthroplasty. A case report. J Bone Joint Surg Am 2008, 90(8):1751-1758

27. Weigel LM, Donlan RM, Shin DH, Jensen B, Clark NC, McDougal LK, Zhu W, Musser KA, Thompson J, Kohlerschmidt D, Dumas N, Limberger RJ, Patel JB: High-level vancomycin-resistant Staphylococcus aureus isolates associated with a polymicrobial biofilm. Antimicrob Agents Chemother 2007, 51(1):231-238

28. Falagas ME, Kapaskelis AM, Kouranos VD, Kakisi OK, Athanassa Z, Karageorgopoulos DE: Outcome of antimicrobial therapy in documented biofilm-associated infections: a review of the available clinical evidence. Drugs 2009, 69(10):1351-1361.

29. Trampuz A, Piper KE, Jacobson MJ, Hanssen AD, Unni KK, Osmon DR, Mandrekar JN, Cockerill FR, Steckelberg JM, Greenleaf JF, Patel R: Sonication of removed hip and knee prostheses for diagnosis of infection. $N$ Engl $J$ Med 2007, 357(7):654-663.

30. Tribble DR, Conger NG, Fraser S, Gleeson TD, Wilkins K, Antonille T, Weintrob A, Ganesan A, Gaskins L, Li P, Grandits G, Landrum ML, Hospenthal DR, Millar EV, Blackbourne LH, Dunne JR, Craft D, Mende K, Wortmann GW, Herlihy R, McDonald J, Murray CK: Infection-associated clinical outcomes in hospitalized medical evacuees after traumatic injury: trauma infectious disease outcome study. J Trauma 2011 , 71(1 Suppl):S33-S42.

31. Eastridge BJ, Jenkins D, Flaherty S, Schiller H, Holcomb JB: Trauma system development in a theater of war: experiences from Operation Iraqi Freedom and Operation Enduring Freedom. J Trauma 2006, 61(6):1366-1372. discussion 1372-1373.

32. Horan TC, Gaynes RP: Surveillance of nosocomial infections. In Hospital Epidemiology and Infection Control. Volume 3. Edited by Mayhall CG. Philadelphia: Lippincott Williams \& Wilkins; 2004:1659-1702.

33. Division of Healthcare Quality Promotion: The National Healthcare Safety Network (NHSN) Manual. Patient Safety Component. Protocol Multidrug-Resistant Organism (MDRO) and Clostridium Difficile-Associated Disease (CDAD) Module. Atlanta, GA: Centers for Disease Control and Prevention; 2008 [http://www idph.state.ia.us/hai_prevention/common/pdf/nhsn4_psc_protocol.pdf]

34. Clinical and Laboratory Standards Institute: Performance Standards for Antimicrobial Susceptibility Testing; Twenty-third Informational Supplement. Volume 33. Wayne, Pennsylvania: CLSI; 2013.

35. Akers KS, Mende K, Yun HC, Hospenthal DR, Beckius ML, Yu X, Murray CK Tetracycline susceptibility testing and resistance genes in isolates of Acinetobacter baumannii-Acinetobacter calcoaceticus complex from a U. S. military hospital. Antimicrob Agents Chemother 2009, 53(6):2693-2695.

36. McDougal LK, Steward CD, Killgore GE, Chaitram JM, MCAllister SK, Tenover FC: Pulsed-field gel electrophoresis typing of oxacillin-resistant Staphylococcus aureus isolates from the United States: establishing a national database. J Clin Microbiol 2003, 41(11):5113-5120.

37. Tenover FC, Arbeit RD, Goering RV, Mickelsen PA, Murray BE, Persing DH, Swaminathan B: Interpreting chromosomal DNA restriction patterns produced by pulsed-field gel electrophoresis: criteria for bacterial strain typing. J Clin Microbiol 1995, 33(9):2233-2239.

38. Linn S: The injury severity score-importance and uses. Ann Epidemiol 1995, 5(6):440-446

39. Ejrnaes K, Stegger M, Reisner A, Ferry S, Monsen T, Holm SE, Lundgren B, Frimodt-Moller N: Characteristics of Escherichia coli causing persistence or relapse of urinary tract infections: phylogenetic groups, virulence factors and biofilm formation. Virulence 2011, 2(6):528-537.

40. Soto SM, Smithson A, Horcajada JP, Martinez JA, Mensa JP, Vila J: Implication of biofilm formation in the persistence of urinary tract infection caused by uropathogenic Escherichia coli. Clin Microbiol Infect 2006, 12(10):1034-1036.

41. Gurung J, Khyriem AB, Banik A, Lyngdoh W, Choudhury B, Bhattacharyya P. Association of biofilm production with multidrug resistance among clinical isolates of Acinetobacter baumannii and Pseudomonas aeruginosa from intensive care unit. Indian J Crit Care Med 2013, 17(4):214-218.

42. Brossard KA, Campagnari AA: The Acinetobacter baumannii biofilm-associated protein plays a role in adherence to human epithelial cells. Infect Immun 2012, 80(1):228-233.

43. Weintrob AC, Murray CK, Lloyd B, Li P, Lu D, Miao Z, Aggarwal D, Carson ML, Gaskins $\sqcup$, Tribble DR: Active surveillance for asymptomatic colonization with multidrug-resistant gram negative bacilli among injured service members-a three year evaluation. MSMR 2013, 20(8):17-22.

44. Obana Y: Pathogenic significance of Acinetobacter calcoaceticus: analysis of experimental infection in mice. Microbiol Immunol 1986, 30(7):645-657.

45. Mastropaolo MD, Evans NP, Byrnes MK, Stevens AM, Robertson JL, Melville SB: Synergy in polymicrobial infections in mouse model of type 2 diabetes. Infect Immun 2005, 73(9):6055-6063.

46. Dalton T, Dowd SE, Wolcott RD, Sun Y, Watters C, Griswold JA, Rumbaugh $\mathrm{KP}$ : An in vivo polymicrobial biofilm infection model to study interspecies interactions. PLoS One 2011, 6(11):e27317.

47. Seth AK, Geringer MR, Hong SJ, Leung KP, Galiano RD, Mustoe TA: Comparative analysis of single-species and polybacterial wound biofilms using a quantitative, in vivo, rabbit ear model. PLOS One 2012 7(8):e42897.

48. Harris AD, Carmeli Y, Samore MH, Kaye KS, Perencevich E: Impact of severity of illness bias and control group misclassification bias in 
case-control studies of antimicrobial-resistant organisms. Infect Control Hosp Epidemiol 2005, 26(4):342-345.

49. Cremet L, Corvec S, Batard E, Auger M, Lopez I, Pagniez F, Dauvergne S, Caroff N: Comparison of three methods to study biofilm formation by clinical strains of Escherichia coli. Diagn Microbiol Infect Dis 2013, 75(3):252-255

50. Rafei R, Dabboussi F, Hamze M, Eveillard M, Lemarie C, Mallat H, Rolain JM, Joly-Guillou ML, Kempf M: First report of bla-producing Acinetobacter baumanii isolated in Lebanon from civilians wounded during the Syrian war. Int I Infect Dis. 2014, 21:21-23.

51. Hochbaum Al, Kolodkin-Gal I, Foulston L, Kolter R, Aizenberg J, Losick R: Inhibitory effects of D-amino acids on Staphylococcus aureus biofilm development. J Bacteriol 2011, 193(20):5616-5622.

52. Kolodkin-Gal I, Romero D, Cao S, Clardy J, Kolter R, Losick R: D-amino acids trigger biofilm dissambly. Science 2010, 328(5978):627-629.

53. Kolodkin-Gal I, Cao S, Chai L, Bottcher T, Kolter R, Clardy J, Losick R: A self-produced trigger for biofilm dissassembly that targets exopolysaccharide. Cell 2012, 149(3):684-692

54. Kim JS, Heo P, Yang TJ, Lee KS, Cho DH, Kim BT, Suh JH, Lim HJ, Shin D, Kim SK, Kweon DH: Selective killing of bacterial persisters by a single chemical compound without affecting normal antibiotic-sensitive cells. Antimicrob Agents Chemother 2011, 55(11):5380-5383.

55. Conlon BP, Nakayasu ES, Fleck LE, LaFleur MD, Isabella VM, Coleman K, Leonard SN, Smith RD, Adkins JN, Lewis K: Activated ClpP kills persisters and eradicates a chronic biofilm infection. Nature 2013, 503(7476):365-370.

doi:10.1186/1471-2334-14-190

Cite this article as: Akers et al:: Biofilms and persistent wound infections in United States military trauma patients: a case-control analysis. BMC Infectious Diseases 2014 14:190.

\section{Submit your next manuscript to BioMed Central and take full advantage of:}

- Convenient online submission

- Thorough peer review

- No space constraints or color figure charges

- Immediate publication on acceptance

- Inclusion in PubMed, CAS, Scopus and Google Scholar

- Research which is freely available for redistribution 